\title{
Homofobia na Escola: As Representações de Educadores/as
}

\author{
Elaine de Jesus Souza ${ }^{\mathbf{1}}$ \\ Programa de Pós-Graduação em Psicologia Social da Universidade Federal de Sergipe, \\ São Cristóvão, SE, Brasil \\ Grupo de Pesquisa Gênero, Sexualidade e Estudos Culturais da Universidade Federal \\ de Sergipe, São Cristóvão, SE, Brasil \\ Joilson Pereira da Silva \\ Núcleo de Pós-Graduação em Psicologia Social da Universidade Federal de Sergipe, \\ São Cristóvão, SE, Brasil \\ Claudiene Santos \\ Departamento de Biologia da Universidade Federal de Sergipe, São Cristóvão, SE, Brasil \\ Lider do Grupo de Pesquisa Gênero, Sexualidade e Estudos Culturais da Universidade \\ Federal de Sergipe, São Cristóvão, SE, Brasil
}

\section{Resumo}

A análise das representações sociais dos/as docentes acerca da homofobia constitui um caminho promissor para estimular a reflexão e a busca de conhecimentos mais coerentes acerca da amplitude dessa violência que, de modo sutil ou manifesto, ocasiona sofrimentos na vida de jovens que não se enquadram no padrão heteronormativo. Portanto, essa pesquisa qualitativa teve como principal objetivo analisar as representações sociais de educadores/as da educação básica acerca da homofobia na escola. Para tanto, foi empregado o método de análise de conteúdo categorial temática e o instrumento constituiu-se de um questionário e entrevista semiestruturada realizados com sete docentes do ensino fundamental maior. Os resultados obtidos revelaram que as representações dos/as docentes acerca da homofobia englobam uma variedade de pensamentos, crenças, ideias pré-estabelecidas e contradições. Pois, além de concepções reducionistas, que definem a homofobia somente como uma aversão ou preconceito contra os homossexuais, sobretudo, devido à carência dessa temática na formação inicial e continuada, também houve algumas concepções mais amplas, que indicam as práticas sutis da homofobia. Assim, esse estudo evidencia a necessidade de mais pesquisas nesse campo, que além da análise das representações de educadores/as, os cursos de formação docente abordem, de modo significativo, os temas diversidade sexual e homofobia, possibilitando intervenções e ações que auxiliem no combate à homofobia (re)produzida no espaço escolar.

Palavras-chave: Homofobia, escola, representações sociais.

\section{Homophobia in School: Representations of Educators}

\begin{abstract}
The analysis of social representations of teachers about homophobia constitute a promising way to stimulate reflection and the search for more coherent knowledge about the extent of this violence that, of subtle or manifest way, cause unnecessary suffering in the lives of young people who do not frame in
\end{abstract}

Endereço para correspondência: Conjunto Caçula Valadares, Rua D, 60, Simão Dias, SE, Brasil 49480-000.

E-mail: elaine.js.sd@hotmail.com, joilsonp@hotmail.com e claudienesan@gmail.com 
heteronormative standard. Therefore, this qualitative study aimed to analyze the social representations of teachers of basic education about homophobia in the school. To this end, we employed the thematic categorical content analysis method and the instrument consisted of a questionnaire and semi-structured interviews conducted with seven greater elementary school teachers. The results revealed that the representations of teachers about homophobia include a variety of thoughts, beliefs, pre-established ideas and contradictions. Because, beyond of conceptions reductionist that define homophobia only as an aversion or prejudice against homosexuals, primarily due to the lack of this theme in the initial and continued training, there was also some broader conceptions, which indicate the subtle practices of homophobia. Thus, this study highlights the need for more research in this field, that in addition to the analysis of representations of educators, teacher education courses address, significantly, the themes sexual diversity and homophobia, enabling interventions and actions that assist to combat homophobia produced and reproduced in the space school.

Keywords: Homophobia, school, social representations.

\section{Homofobia en la Escuela: Las Representaciones de Educadores}

\section{Resumen}

El análisis de las representaciones sociales de los maestros sobre la homofobia es una forma prometedora para estimular la reflexión y la búsqueda del conocimiento más coherente sobre el alcance de esta violencia, de manera sutil o evidente, causar sufrimiento innecesario en la vida de los jóvenes que no se ajustan al estándar heteronormative. Por lo tanto, este estudio tuvo como objetivo analizar las representaciones sociales de los maestros de educación básica sobre la homofobia en la escuela. Para ello, se utilizó el método de contenido categorial temático. Los resultados revelaron que las representaciones de los maestros sobre la homofobia abarcan una variedad de pensamientos, creencias, ideas preestablecidas y contradicciones. Porque además de la reducción de las concepciones que definen la homofobia sólo como una aversión o el prejuicio contra los homosexuales, sobre todo debido a la falta de este tema en la formación inicial y continua, también hubo algunas concepciones más amplias, que indican las prácticas sutiles de homofobia. Así, este estudio pone de relieve la necesidad de más investigación en este campo, además del análisis de las representaciones de los educadores, los cursos de formación del profesorado que abordan, de manera significativa, los temas de la diversidad sexual y la homofobia, permitiendo intervenciones y acciones que ayuden a combatir la homofobia producido y reproducido dentro de la escuela.

Palabras clave: Homofobia, escuela, representaciones sociales.

O estudo das Representações Sociais de educadores/as acerca da homofobia, aliado a outras ações interventivas, pode colaborar com a desestabilização das práticas preconceituosas e discriminatórias que são manifestadas contra a diversidade sexual, nas diversas instâncias sociais, inclusive na instituição escolar.

Em consonância com os Parâmetros Curriculares Nacionais (PCN; Secretaria de Educação Fundamental, 1999) e o Programa Brasil Sem Homofobia (Conselho Nacional de Combate à Discriminação [CNCD] \& Ministério da Saúde, 2004), destaca-se que o processo de in- clusão da diversidade sexual e enfretamento da homofobia demandam além do envolvimento significativo dos/as educadores/as para a formação de cidadãos/ãs críticos/as e conscientes, a adoção de uma postura pluralista e democrática. Destarte, a colaboração ativa dos/as docentes, através da promoção de medidas pedagógicas que favoreçam o reconhecimento e o respeito à diversidade sexual na escola, pode contribuir para o combate as várias formas de violação dos direitos humanos dos grupos de Lésbicas, Gays, Bissexuais e Travestis e Transexuais (LGBT). 
Nessa perspectiva, ressalta-se que entre às medidas públicas de combate à homofobia, uma das principais iniciativas ocorreu em 2004 quando a Secretaria Especial de Direitos Humanos lançou o Brasil Sem Homofobia, um programa de combate à violência e à discriminação contra LGTB e de promoção da cidadania homossexual (CNCD \& Ministério da Saúde, 2004). Tal programa tem como principal objetivo: “. . . promover a cidadania de gays, lésbicas, travestis, transgêneros e bissexuais, a partir da equiparação de direitos e do combate à violência e à discriminação homofóbicas, respeitando a especificidade de cada um desses grupos populacionais" (CNCD \& Ministério da Saúde, 2004, p. 11).

Os Ministérios e Secretarias do Governo Federal do programa Brasil sem Homofobia assumiram o compromisso de combater a homofobia, através da promoção de uma mudança de comportamento da sociedade brasileira em relação à LGBT, estabelecendo políticas inclusivas que impulsionem a aceitação e o respeito à diversidade (CNCD \& Ministério da Saúde, 2004). Contudo, para colocar em prática o que preconiza esse documento são necessárias intervenções sociais significativas e a formação inicial e continuada de profissionais, isto é, ações de diversas esferas sociais que possibilitem o reconhecimento da diversidade e a garantia de seus direitos. A instituição escolar exerce função primordial, pois através de seus membros pode multiplicar conhecimentos imprescindíveis para a desconstrução de preconceitos e discriminações.

Entre as pesquisas realizadas no Brasil acerca da homofobia, a de maior impacto foi a conduzida pela Organização das Nações Unidas para a Educação, a Ciência e a Cultura (UNESCO) em 13 capitais brasileiras e no Distrito Federal contando com uma amostra de 16.422 estudantes, 241 escolas, 4.532 pais e 3.099 educadores/as e funcionários de escolas (Abramovay, Castro, \& Silva, 2004). Tal pesquisa evidenciou os efeitos da falta de formação no campo da sexualidade e a amplitude da rejeição da diversidade sexual no âmbito escolar (Abramovay et al., 2004; Nardi, 2010).

Outra relevante pesquisa foi a coordenada pela Fundação Perseu Abramo (FPA) que ao investigar a violência homofóbica no Brasil evidenciou, no país, um cenário de intensa opressão a que milhões de pessoas são submetidas cotidianamente de forma direta ou indireta. Desse modo, um problema tão grave e que afeta tantos jovens permanece invisível nas diversas instâncias sociais e é colocado entre as últimas prioridades das esferas públicas (Prado \& Junqueira, 2011).

Nesse viés, salienta-se a necessidade de promover ações interventivas que permitam desconstruir práticas homofóbicas e, é indispensável analisar a percepção dos sujeitos envolvidos na mudança de comportamento, principalmente, educadores/as, que perpetram ou são alvos de homofobia.

A homofobia pode ser entendida como uma forma de preconceitos e/ou discriminações (e demais violências daí decorrentes) contra indivíduos ou grupos sociais que não se enquadram no padrão heterossexual em função de sua orientação afetivo-sexual e/ou identidade de gênero pressupostas e, neste conceito estão incluídos a lesbofobia, a gayfobia, a transfobia, bifobia, ou seja, a "LGBTfobia" em geral (Secretaria de Direitos Humanos, 2012).

Dessa forma, o conceito homofobia visto de forma abrangente, passa a englobar os preconceitos e discriminações perpetrados contra lésbicas, gays, bissexuais, travestis, transexuais e outras formas de diversidade sexual, em decorrência dos seus comportamentos, estilos de vida e aparências divergentes dos padrões heteronormativos impostos. E, portanto, envolve elevado grau de violação dos direitos humanos de tais indivíduos e/ou grupos sociais. Assim, o conceito de homofobia não se restringe e centra-se somente no indivíduo e na sua "reação anti-homossexual", mas se estende além, visto que, envolve aspectos culturais, educacionais, políticos, institucionais, jurídicos, antropológicos que demandam a reflexão, crítica e denúncia acerca da imposição de normas sexuais e de gênero (Junqueira, 2009; Rios, 2009).

Tosso (2012, p. 236) acrescenta que “. . . el concepto homofobia, se alude no sólo al rechazo a las personas homosexuales, sino también al rechazo a las personas bisexuales y transexuales, 
tengan esa orientación sexual o solamente aparenten tenerla".

Embora o presente trabalho adote o termo homofobia nessa perspectiva ampla, cabe expor que Herek (2000) emprega o termo preconceito sexual para se referir a todas as atitudes negativas com base na orientação (afetivo) sexual, isto é, contra grupos ou indivíduos com identidades sexuais (lésbicas, gays, bissexuais) e de gênero (travestis e transexuais) distintas da norma heterossexual. Assim, tal preconceito também atinge sujeitos heterossexuais que são rotulados de lésbicas, gays ou bissexuais por adotarem comportamentos e/ou papeis divergentes do modelo heteronormativo. Como os outros tipos, o preconceito sexual abarca três características principais: é uma atitude (uma avaliação ou julgamento) negativa que é dirigida a um grupo social e seus membros e, envolve também antipatia e hostilidade.

Para Moscovici (2010) “. . . todos os nossos 'preconceitos', sejam nacionais, raciais, geracionais ou quaisquer que alguém tenha, somente podem ser superados pela mudança de nossas representações sociais da cultura, da "natureza humana' e assim por diante ...” (p. 66).

Assim, por intermédio da teoria das representações sociais, investiga-se, nesse trabalho, de que forma os conhecimentos, vivências e concepções dos/as educadores/as ancoram a homofobia.

Por conseguinte, Chaves e Silva (2011) apontam que:

... a teoria das representações sociais oferece um excelente suporte às investigações na medida em que pauta a sua investigação a partir do conhecimento do sujeito ou grupo estudado, e como esse conhecimento orienta as suas práticas cotidianas. (p. 348)

As representações sociais constituem sistemas de interpretação que orientam e organizam as comunicações e comportamentos sociais, pois determinam nossa relação com o mundo e com os outros. E, desse modo, intervêm em diversos processos, tais como no desenvolvimento individual e coletivo, na difusão e assimilação de conhecimentos, bem como na definição de identidades pessoais e sociais, na manifestação dos grupos e nas transformações sociais (Jodelet, 1989/1993) que permitem superar preconceitos.

Cabe enfatizar que: “. . . preconceitos são, portanto, atitudes, e como tais se constituem em julgamentos antecipados que têm componentes cognitivos (as crenças e os estereótipos), afetivos (antipatias e aversões) e disposicionais ou volitivos (tendências para a discriminação)" (Lima, 2011, p. 459). Assim, percebe-se que os preconceitos (manifestos ou sutis) criados em torno da diversidade sexual que caracterizam a homofobia, provém, na maioria dos casos, do desconhecimento que ocasiona representações precipitadas e arbitrárias. Logo, percebe-se que a ausência da experiência e da reflexão, que constituem as bases do indivíduo, pode caracterizar ou promover as distintas nuances do preconceito (Chochík, 2006).

Nesse caminho, aponta-se a existência de duas formas de expressão do preconceito: manifesto ou sutil. $\mathrm{O}$ primeiro refere-se às formas abertas e ativas manifestadas de modo evidente através de atitudes negativas, denominado preconceito manifesto ou flagrante. O segundo é o preconceito sutil, uma nova forma de expressão caracterizada por um discurso camuflado ou velado que encobre os reais sentimentos e crenças acerca de determinado indivíduo ou grupo social, não obstante a sutileza, disfarçada de tolerância perpetua as desigualdades sociais (Fleury \& Torres, 2010; Lima \& Vala, 2004; Silva, 2010).

Dessa forma, a homofobia consiste em um fenômeno complexo e variado que envolve distintas formas de preconceitos (sutis ou manifestos) e discriminações expressas em diversos âmbitos sociais, por meio de violências psicológicas (agressões verbais, distinções, exclusões, restrições ou preferências) e violências físicas que anulam e prejudicam o reconhecimento e o exercício pleno da cidadania por parte da diversidade sexual. A gravidade da homofobia não consiste somente nas práticas de violência física, mas também nas manifestações da violência psicológica presente nos insultos, nas piadas, na linguagem cotidiana, entre outras manifestações que violam direitos humanos básicos e essenciais de um indivíduo que é julgado inferior apenas por sua identidade sexual e/ou de gênero 
ser contrária às normas sociais impostas de forma arbitrária (Borrilo, 2009; Louro, 1997; Rios, 2009).

Nesse contexto, a manutenção de crenças, opiniões, preconceitos e práticas que compõem as representações de educadores/as, reforçam as violências homofóbicas perpetradas contra indivíduos que não se enquadram no "convencional", ou seja, no padrão heterossexual denominado heteronormatividade (Louro, 2001). Entretanto, as representações sociais apesar de terem caráter convencional e prescritivo (Moscovici, 2010) também podem possuir caráter construtivo que admite reconstruções (Jodelet, 1989/1993), dessa forma, as representações sociais podem ser utilizadas para transformar palavras, categorias, assuntos (como a diversidade sexual) em algo familiar e significativo.

Destaca-se que as representações sociais podem ser utilizadas para expressar alteridade, lutando pela compreensão, interpretação e construção de um mundo que envolve uma diversidade de sujeitos que ocupam o espaço público. Portanto, surge a necessidade de defender essa vida em comum, que é frequentemente ameaçada por variados tipos de desigualdades, preconceitos e outras violências. Para isso, ressalta-se a extrema relevância de recuperar o pensamento, a palavra e a construção de saberes sociais, como formas de sustentar a democracia e a cidadania, em que a diversidade de indivíduos e grupos sociais consiga usufruir plenamente seus direitos sejam sexuais, socioculturais, políticos, entre outros (Jovchelovitch, 2008).

É perceptível a complexidade do tema homofobia tanto para os/as pesquisadores/as que estudam as violências na escola, quanto para os/ as docentes, visto que envolve educação para a sexualidade, estudos sobre gênero e diversidade sexual, orientação e identidade sexual, bem como inclusão/exclusão. Portanto, analisar as representações acerca desse tema é um enorme desafio, levando-se em consideração a amplitude de questões polêmicas que o tema engloba, e também por ser um assunto tão velado na escola (e na sociedade de um modo geral), mas, que ao mesmo tempo apresenta uma diversidade de opiniões, crenças e conceitos (Koehler, 2009).
A concepção da heteronormatividade, compartilhada e (re)produzida pela escola, além do parco conhecimento sobre as questões que perpassam a homofobia nesse âmbito, contribuem para a ocorrência de preconceitos, discriminações e diversas violências contra homossexuais, bissexuais, transgêneros, entre outros. A omissão de um assunto tão importante, que necessita ser debatido e abordado no espaço escolar, pode ocasionar práticas homofóbicas (Cavaleiro, 2009; Louro, 2009).

Dessa forma, o silenciamento e a negação da homofobia no âmbito escolar podem corroborar em práticas de omissões, discriminações, conivências com as múltiplas formas de violência cotidianas, que se manifestam pelo afastamento, desprezo e segregação dos indivíduos discordantes da norma heterossexual hegemônica. Então, cria-se uma enorme resistência em demonstrar simpatia com indivíduos que possuem orientações afetivo-sexuais distintas do padrão heteronormativo, ou simplesmente que não se enquadram nos arbitrários estereótipos de gênero (padrão masculino ou feminino binários criados pela sociedade). Visto que, em geral, para os homofóbicos é como se a homossexualidade fosse "contagiosa", logo, qualquer aproximação pode ser interpretada como uma adesão a tal identidade ou prática sexual (Louro, 2000).

Nesse viés, é perceptível que além das diferenças individuais, a principal influência para o desenvolvimento de preconceitos é a possibilidade de ter ou não experiências e realizar reflexões acerca de si mesmo e sobre os outros nas relações sociais, que podem ser facilitadas ou dificultadas pelas diversas instituições sociais que permeiam os processos de socialização. Então, as representações acerca do conhecimento do mundo dependem da qualidade da ação das instituições, como a família, escola, mídia, ou seja, da forma como elas tratam e (re)produzem assuntos polêmicos, como a diversidade sexual (Chochík, 2006).

Lima (2011) depreende que, independente das estratégias ou medidas empregadas para combater as diversas manifestações preconceituosas, é preciso se atentar para a urgência e complexidade dessa tarefa. A intervenção necessária 
ao enfrentamento das discriminações advindas do preconceito demanda uma articulação de meios, parcerias e ações para evitar que os indivíduos sejam alijados de determinados direitos e passem por privações como ter acesso restrito aos recursos materiais e simbólicos, somente por possuírem uma marca grupal, objetiva ou impingida, socioculturalmente desvalorizada. Ou seja, o simples fato de julgar a identidade sexual e/ ou de gênero de determinado indivíduo já leva à criação de estereótipos que culminam em várias práticas homofóbicas.

Dessa maneira, é urgente a necessidade de uma formação inicial e/ou continuada que sensibilize os/as docentes para acolher essa diversidade de sujeitos e adotar estratégias para impedir (ou ao menos reduzir) quaisquer tipos de preconceito e discriminação. A escola deve ser um ambiente de reflexão e cidadania, em que prevaleçam os direitos humanos (Cavaleiro, 2009) e a formação de cidadãos/ãs críticos/as.

Scardua e Souza (2006) assinalam que a análise, compreensão e reconstrução das representações sociais pode ser um instrumento fundamental para a descrição e explanação dos saberes e conhecimentos socialmente elaborados e difundidos. Sendo assim essenciais para lidar com eventos, assuntos, indivíduos e grupos considerados estranhos e indefinidos que não se enquadram nos padrões socioculturais dos grupos mais numerosos, como é o caso da homossexualidade e de outras identidades sexuais distintas do modelo heteronormativo.

Dessa forma, enfatiza-se a necessidade de intervenções para que ocorram mudanças nas normas socioculturais e em representações que reforçam as violências contra LGBT e estimulam sentimentos e práticas homofóbicas. É necessário questionar e problematizar que historicamente a heterossexualidade é tida como a norma ou padrão, bem como reconhecer a existência e a manutenção da homofobia e compreender a existência de distintas relações sociais que são construídas na própria escola, apontando a importância de (re)conhecer as múltiplas identidades sexuais e de gênero como parte das profundas mudanças na sociedade. Portanto, o/a educador/a pode ser um/a protagonista fun- damental nas relações da escola, como sujeito ativo, capaz de intervir e transformar (Koehler, 2009) a realidade social, começando pela reconstrução de suas representações sociais, através dos processos de ancoragem e objetivação, que permitem a substituição das ideias e crenças preestabelecidas por saberes novos, dinâmicos e em favor da diversidade (Jodelet, 1989/1993).

Por isso, elencar as representações sociais dos/as docentes acerca da homofobia constitui um caminho promissor para estimular a reflexão e a busca de conhecimentos mais coerentes acerca da amplitude dessa violência que, de modo sutil ou manifesto, ocasiona tantos sofrimentos na vida de jovens que não se enquadram no padrão heteronormativo.

Nesse sentido, este trabalho tem como objetivo: analisar as representações sociais de educadores/as da educação básica (ensino fundamental maior) acerca da homofobia. Para tanto, a pesquisa buscou responder as seguintes questões norteadoras: (a) Quais os principais conteúdos das representações sociais de educadores/ as acerca da Homofobia? (b) Como os conhecimentos e vivências dos/as educadores/as ancoram a homofobia na escola?

\section{Método}

Essa pesquisa qualitativa foi realizada em uma escola pública do município de Simão Dias (Sergipe). A escolha desse lócus deve-se à escassez de estudos acerca dessa temática no interior de Sergipe. Os/as participantes da pesquisa foram sete professores/as do ensino fundamental maior ( $6^{\circ}$ ao $9^{\circ}$ ano), das disciplinas de Português, Matemática, Ciências, Geografia, História, Inglês e Educação Física. Essa escolha justifica-se por corresponderem às disciplinas obrigatórias e que devem abordar os temas transversais de modo interdisciplinar, inclusive a questão da sexualidade e da diversidade sexual.

Nessa direção, cabe expor os principais dados sociodemográficos dos/as docentes participantes, destacando os nomes fictícios adotados na pesquisa. A saber: a professora de Português, Camila, tem 23 anos de idade, possui experiência de mais de 2 anos na educação básica e sua 
religião é católica; Roberta é graduada em Matemática, tem 41 anos, e experiência docente de 21 anos, também é católica; o professor de Ciências, Antônio, tem 33 anos e atua na área da educação há 14 anos, é católico; Lúcio, professor de Geografia, tem 30 anos e atua na profissão há 3 anos, católico; a professora de História, Claudia tem 49 anos e experiência docente de 23 anos, sua religião é evangélica; Samuel, professor de Inglês tem 30 anos, com cerca de 4 anos de atuação na área e é católico; e por fim a professora de Educação Física, Talita, tem 24 anos e atua há 4 anos como docente, é católica

Vale ressaltar que os/as participantes da pesquisa lecionam em uma escola pública estadual localizada no interior sergipano, porém, a maioria reside na capital do Estado. Embora seja de pequeno porte, a escola A conta com aproximadamente 300 alunos/as matriculados/as e um quadro de 15 funcionários, entre professores/as, equipe diretiva e pessoal de apoio. Nessa escola funciona a modalidade de ensino fundamental menor ( $3^{\circ}$ ao $5^{\circ}$ ano) e maior ( $6^{\circ}$ ao $9^{\circ}$ ano), e existem na instituição sete docentes licenciados/ as nas disciplinas de ensino obrigatórias. A escola costuma realizar semanas especiais com palestras acerca de temas de interesse dos/as adolescentes, contudo, ainda não focaliza a questão da diversidade sexual, entre outros motivos devido à falta desses temas durante a formação inicial e continuada dos/as docentes, o que contribui para representações ancoradas em crenças preestabelecidas.

Para coleta de informações foi elaborado um instrumento constituído por um questionário para auxiliar na entrevista semiestruturada, ambos desenvolvidos com base na bibliografia estudada (Dinis, 2012; Madureira, 2007; Silva, 2010; Tosso, 2012).

Inicialmente, o projeto foi enviado e aprovado pelo Comitê de Ética. Posteriormente, foi solicitada a autorização das escolas para os/as educadores/as participarem da pesquisa. Os/as docentes assinaram termos de consentimentos livres e esclarecidos, bem como foi aplicado um questionário com questões abertas e fechadas sobre homofobia na escola e, em seguida, realizadas as entrevistas semiestruturadas.
Empregou-se a análise de conteúdo categorial temática para analisar as informações obtidas. Desse modo, foram discriminadas as unidades de sentido do texto, ou seja, as principais opiniões, crenças e tendências encontradas nas respostas dos questionários e das entrevistas, e posteriormente, essas unidades foram agrupadas em categorias de análise (Bardin, 2011) facilitando a compreensão das principais representações dos/as educadores/as acerca da homofobia na escola.

De modo sintético, pode-se dizer que análise categorial temática, feita após a transcrição integral dos questionários e das entrevistas, começa com a divisão do texto em alguns temas principais. Após, a delimitação dos temas, busca-se determinar as características associadas ao tema central, visando extrair os significados associados a cada tema (Bardin, 2011). E desse modo, foram delimitadas as categorias que permitem descrever os principais resultados da pesquisa.

\section{Resultados e Discussão}

Os resultados obtidos foram agrupados em duas categorias: "Representações acerca da Homofobia: o que dizem os/as docentes?", que engloba as principais crenças e opiniões que constituem os conteúdos das representações dos/ as docentes acerca da homofobia; e "Homofobia no Espaço Escolar: vivências de educadores/as", que inclui as principais vivências dos/ as educadores/as acerca da homofobia na escola.

\section{Representações Acerca da Homofobia: O que Dizem os/as Docentes?}

As representações dos/as docentes acerca da homofobia evidenciaram contradições, pois apesar do desconhecimento acerca da amplitude dessa violência, revelaram algumas concepções mais amplas e outras reducionistas. As respostas reduzem a homofobia apenas à aversão ou preconceito contra os homossexuais, o que pode ser compreendido pelo entendimento literal do termo e pela falta de conhecimentos acerca desses temas durante a graduação ou na ausência de formação continuada. As seguintes unidades temáticas mostram as principais concepções dos/ 
as educadores/as acerca do conceito de homofobia:

"Aversão a homossexuais" (Prof. ${ }^{\mathrm{a}}$ Roberta). "Medo de assumir o que realmente possa ser, devido ao preconceito da família e da própria sociedade" (Prof. Antônio).

"Prática de intolerância contra pessoas" (Prof. Lúcio).

"Preconceito contra homossexuais, aversão ou discriminação seja de formas sutis ou não" (Prof. ${ }^{\text {a Claudia). }}$

"Medo do semelhante, atualmente termo usado para descrever o preconceito e a violência contra os homossexuais" (Prof. Samuel). "É uma aversão aos homossexuais" (Prof. Talita).

É necessário esclarecer que embora o conceito de homofobia tenha sido empregado inicialmente para se referir a um conjunto de emoções negativas (aversão, desprezo, ódio ou medo) em relação à homossexualidade, essa noção foi alargada para englobar as múltiplas faces da violência homofóbica. Ao superar o entendimento limitado e centrado exclusivamente nos sentimentos e atitudes de indivíduos, começa-se a pensar o enfrentamento da homofobia a partir de medidas e políticas públicas que promovam mudanças significativas nas instituições, como a escola. Assim, a homofobia é representada como um fenômeno psicológico e social que está ancorada nas complexas relações estabelecidas entre uma estrutura psíquica e uma organização social normativa que considera a heterossexualidade como ideal no campo afetivo-sexual. No âmbito social e escolar, outras manifestações insidiosas exercem suas violências cotidianamente (como nos insultos, piadas e ironias), pois esta outra face da homofobia, mais eufemística e de cunho social, ancora-se na atitude de desdém constitutiva de uma forma habitual de aprender e de categorizar o outro (Borrilo, 2009, 2010; Junqueira, 2009), ou seja, uma forma normatizante de representar as diferenças de modo hierárquico e assimétrico, no caso da diversidade sexual.

As representações dos/as docentes denotam um conjunto de pensamentos, crenças e ideias pré-estabelecidas em torno da homofobia, ou seja, é marcante a presença de normatizações em torno desse conceito. O que confirma que as representações constituem um fenômeno psicossocial que está ancorado tanto na esfera pública quanto nos processos que possibilitam aos indivíduos construir suas identidades, criando símbolos e se abrindo para a diversidade através dos núcleos positivos de transformação que decorrem da efetiva objetivação do conhecimento "novo", ou em contraponto ancoram-se em núcleos resistentes à compreensão da realidade além das normas. É desse modo que a visão dos grupos sociais acerca de determinado objeto (nesse caso a homofobia) expressam as contradições em que foram produzidas (Jovchelovitch, 2008; Minayo, 2008).

Nas entrevistas, quando indagados/as acerca de suas concepções, vivências e práticas acerca da diversidade sexual e da homofobia, os/as docentes revelaram as seguintes concepções, opiniões e crenças acerca da homofobia:

"É o preconceito, né que se tem contra o homossexualismo, né é aquela aversão que as pessoas têm contra a prática do homossexualismo e que..." (Prof. ${ }^{\text {a Claudia). }}$

A homofobia é complicado porque é uma coisa que nos deparamos diariamente na sociedade, né? O preconceito com as pessoas homossexuais... Porque eu sou católica econcordo em eles adotarem um filho, porém não concordo que eles casem ... (Prof. ${ }^{\text {a Camila) }}$ "Então, eu acho que a homofobia .. . é um preconceito como outro mesmo qualquer. É ... porque a gente tem agressões a negros, aos nordestinos, bem como homossexuais" (Prof. Samuel).

"Homofobia é quando uma pessoa rejeita né, tem uma aversão à questão dos homossexuais" (Prof. ${ }^{\text {a }}$ Talita).

Homofobia, na verdade são pessoas que se sentem incomodadas com essas pessoas que tem uma condição de vida diferente daquilo que prega a sociedade, né? Um sujeito que não gosta de estar em lugares que tenham esse tipo é... essas pessoas que tem uma opção sexual diferente da deles. (Prof. Lúcio)

Os discursos acima englobam as representações reducionistas acerca da homofobia, que foram apreendidas também nos questionários, 
visto que, de um modo geral, a maioria dos/as educadores/as compreendem a homofobia somente na dimensão do preconceito, aversão e rejeição aos homossexuais. É visível que a ideia literal do termo homofobia ainda prevalece devido à falta de informações atualizadas acerca de um tema tão relevante para o âmbito escolar. Em decorrência do desconhecimento, o uso de termos inadequados ("homossexualismo", "condição", "opção sexual") foi recorrente nas falas dos/as docentes. Além disso, a influência da religião também pôde ser vislumbrada nas representações.

Apesar da mudança de tom, subsiste a homofobia enraizada nas crenças e dogmas religiosos, contudo, ao invés de lançar os sodomitas na fogueira, agora, sob o viés do preconceito sutil, a homofobia cognitiva e a liberal preconizam a complacência, compaixão e a tolerância, para que na melhor das hipóteses os/as homossexuais (e outros que fogem às normas) sejam "curados/ as" ou possam viver na abstinência. Assim, a hostilidade da Igreja e de outras instâncias sociais (inclusive a escola) acerca da diversidade sexual é, atualmente, muito mais sutil, visto que as práticas homofóbicas não se referem somente à condenação ou rejeição dos/as homossexuais, mas promovem o indiferencialismo subjacente ao liberalismo contemporâneo (Borrilo, 2010). Isso caracteriza a homofobia cognitiva ou social a qual, apesar de incentivar a tolerância e o respeito, não problematiza a marginalização da diversidade e muito menos se incomoda com a manutenção das diferenças de direitos humanos. De modo semelhante, a homofobia liberal envolve uma forma de privação da liberdade de expressão sexual no espaço público (Borrilo, 2009; Tosso, 2012).

Nesse sentido, destaca-se a homofobia liberal que engloba o preconceito sutil, camuflado, velado, e é caracterizada pela aceitação aparente das pessoas homossexuais, pois "permite-se" sua existência desde que não manifestem as características e comportamentos contrários às normas sexuais e de gênero no espaço público. Assim, a tolerância à diversidade sexual reitera a manutenção da norma (Borrilo, 2009; Tosso, 2012), pois, como assevera Furlani (2009), a tolerância pressupõe uma hierarquização entre quem tolera e quem é tolerado e não resulta em garantia de direitos e inclusão.

O preconceito sutil constitui uma forma de expressão dos julgamentos antecipados que pode ser considerada o produto da propagação de uma "cultura igualitária" (Fleury \& Torres, 2010). Dessa maneira, entende-se que: “. . . O fenômeno se adequou a novos valores, novas ideologias, novas normas sociais, produzindo uma nova modalidade de pensamento e expressão do preconceito que atende a essa nova realidade" (Fleury \& Torres, 2010, p. 79).

É justamente porque quase ninguém admite ter preconceitos que, com frequência, ouvimos as pessoas dizerem: "Não tenho preconceito, mas não gosto de homossexuais". O que evidencia contradições, pois embora quase ninguém assuma ter preconceitos, já que esse termo remete a ignorância e a intolerância, os discursos revelam os pré-julgamentos, ainda que expressos de modo sutil ou latente (Fleury \& Torres, 2010).

Em contraponto, quando os/as educadores/ as foram indagados/as se a homofobia deve ser considerada crime, $100 \%$ afirmaram que sim, justificando, de um modo geral, que esta constitui uma forma de preconceito e discriminação que causa sofrimentos físicos e psicológicos aos indivíduos não heterossexuais.

"Sim. Pois devido termos uma sociedade muito preconceituosa, faz com que evite o máximo esse tipo de atitude" (Prof. Antônio).

"Sim. Pois devemos respeitar todos independente da orientação sexual" (Prof. a Camila).

"Sim, todo atentado à vida humana, tem que ser considerado crime" (Prof. Lúcio).

"Acho que qualquer forma de discriminação e preconceito, se extrapolada com violência física ou psicológica e que cause constrangimento a vítima, deve ser crime" (Prof. Samuel).

"Sim, já que temos livre arbitrio para escolher o que queremos ser, isso tem que ser respeitado" (Prof. ${ }^{\text {a }}$ Roberta).

"Sim. A liberdade do homem é algo sagrado e essencial, para a vida ninguém tem o di- 
reito de interferi na escolha do outro, usando da violência seja física ou psicológica" (Prof. ${ }^{\text {a }}$ Claudia).

"Sim, porque ninguém tem o direito de agredir uma pessoa por causa da sua escolha sexual" (Prof. ${ }^{\text {a }}$ Talita).

A homofobia envolve diferentes práticas de preconceito e discriminação manifestadas em diversos âmbitos sociais, por meio de segregações, desigualdades e privações que prejudicam o reconhecimento e o exercício pleno da cidadania por parte da diversidade sexual. Portanto, é inegável que a homofobia representa um ato violento e criminoso não somente quando envolve agressões físicas, mas também à medida que viola direitos sexuais e humanos de um indivíduo julgado inferior apenas por sua identidade sexual ser divergente das normas sociais impostas de modo arbitrário (Borrilo, 2009; Rios, 2009).

Em face do desconhecimento e/ou precariedade da formação inicial e continuada de docentes diante da complexidade da homofobia, urge intervir nessa realidade a fim de superar o silêncio e a negação em torno desse assunto polêmico que abriga uma gama de crenças, opiniões e conceitos tanto no discurso acadêmico quanto no senso comum (Koehler, 2009; Louro, 1997).

\section{Homofobia no Espaço Escolar: Vivências de Educadores/as}

Acerca das vivências e práticas relativas à homofobia na escola, os/as docentes revelaram ter presenciado situações de preconceitos e, sobretudo agressões psicológicas. No entanto, é perceptível que alguns/mas professores/as ainda não entendem a gravidade dos insultos e apelidos pejorativos. A agressão física é reconhecida como uma forma grave de homofobia, contudo, por vezes os/as docentes banalizam as violências verbais e psicológicas e, em alguns casos até participam das agressões preconceituosas, consideradas por eles/as "brincadeirinhas". Foi ressaltada a influência da formação sociocultural tradicionalista na ocorrência e manutenção da homofobia e de outras formas de preconceitos que permeiam a sociedade e o ambiente escolar, dessa forma tais práticas de homofobia sutil ocasionam graves consequências na vida de jo- vens que diferem do padrão heterossexual. Tais representações podem ser notadas nos discursos abaixo:

“. . . já vi insultos, humilhações já me deparei com essas situações diariamente. Em questão de diversidade sexual, a homofobia e o preconceito, que nos deparamos diariamente com a sociedade, infelizmente" (Prof. ${ }^{\text {a Camila). }}$

"A gente sempre presencia, né? É... um assunto que a gente acaba, às vezes, brincando, né? Entre aspas. Mas sempre tem o preconceito por trás. Até, até eu mesmo, às vezes, brinco" (Prof. Samuel).

“. . . na escola. Não, assim mais brigas, né? Assim, eu não prestava muita atenção, mas chamava, né? Normal, 'bicha', 'não sei o que', ai ele revidava" (Prof. Lúcio).

"[Casos] de homofobia não. A gente vê,. . . às vezes os coleguinhas: 'Ah, é viado! $E$ ' isso, é aquilo...', mas algum caso esporádico, um ou outro, intervém... Em sala de aula, durante o intervalo, né? (Prof. ${ }^{\text {a }}$ Roberta). . . As piadinhas sempre existem, né porque nem precisa ele saber que realmente a pessoa é assumida, se ele... de vez em quando com algum professor, ai a gente ... por longe você percebe aquelas piadinhas, né? . . Que ainda existe né, a gente sabe que o preconceito ainda existe, de forma sutil, mas existe! (Prof. ${ }^{a}$ Claudia)

Embora a homofobia constitua uma violência psicológica e social, a maioria das pessoas ainda não a representa como tal. Contudo, deve-se atentar que quando tais violências são interiorizadas sob a forma de injúrias, afirmações desdenhosas, insultos, condenações morais ou atitudes compassivas ocasionam graves consequências na vida de jovens não heterossexuais. Pois, estes para evitar os preconceitos acabam tendo que lutar contra seus desejos, tentando rejeitar sua própria sexualidade, e então, experienciam sofrimentos, como sentimentos de culpa, ansiedade, vergonha, depressão, o que os leva à exclusão social e em alguns casos até ao suicídio. Desse modo, a interação entre os aspectos psicológicos e sociais deve ser questionada para se compreender melhor os elementos constantes 
que facilitam, estimulam ou banalizam a homofobia (Borrilo, 2010).

Ainda com relação às violências homofóbicas manifestadas no cenário escolar, os/as professores/as relataram as seguintes ocorrências que salientam a presença do bullying homofóbico ocasionado, na maioria dos casos, pelo preconceito "sutil".

"E eu vi inúmeras vezes causando a questão de constrangimento com a questão dos colegas, brigas, intrigas verbais entre ambas as partes, agressões mesmo com palavrões e tudo" (Prof. Antônio).

. . . a gente sempre presencia os próprios colegas, os próprios meninos. Mangando, né. Fazendo bullying com os colegas, só pelo fato de ele parecer ser homossexual, porque na verdade quando crianças não são homossexuais ainda, né? Mas pelo jeito, pelas atitudes. (Prof. Samuel)

. . . ai eu tinha um aluno, que por sinal ele tinha sido meu aluno desde a segunda série, E... aí você percebia não por parte dos colegas, mas... assim... pessoas de outras turmas, que tinha sim aquela pressão, além do bullying que fazia, você percebia que tinha pessoas que se afastavam, que criticavam. (Prof. ${ }^{a}$ Claudia)

... E a prática assim dentro da escola, essas brincadeiras, que eu acho que são piores até do que às vezes até uma agressão fisica que machuca, mas depois cicatriza com o tempo, mas a verbal que a palavra em si,é pro resto da vida néfica na sua consciência. (Prof. ${ }^{\text {a }}$ Talita)

O bullying homofóbico constitui os preconceitos, discriminações e agressões verbais que são manifestados na escola contra alunos/as não heterossexuais ou que fogem aos estereótipos de gênero. Destarte, salienta-se que uma das faces do preconceito é resultante do processo de socialização que impõe normas acerca dos papeis e características de cada indivíduo. Existem várias nuances de preconceito (nesses casos, sexuais), que podem ser expressas, de forma mais evidente através da rejeição e discriminação direta, ou de modo sutil, representada por violências psicológicas caracterizadas pela não aceitação da diversidade sexual e por atitudes preconceituosas, tais como apelidos pejorativos, piadinhas, que podem ser denominadas Homofobia indireta (Borrilo, 2009; Chochík, 2006; Rios, 2009; Silva, 2010).

De modo contraditório, as representações dos/as professores/as acabam sinalizando a amplitude da homofobia. Visto que, as práticas homofóbicas envolvem desde as discriminações diretas e intencionais que remetem à rejeição dos indivíduos não enquadrados na heteronormatividade, caracterizando também a homofobia psicológica, até as discriminações indiretas ou não intencionais que podem ser representadas pela homofobia cognitiva ou social. Porém, independente de suas facetas, a homofobia consiste em um fenômeno individual e sociocultural complexo que engloba preconceitos e discriminações contra sujeitos com identidades sexuais e de gênero não normativas e, portanto, sempre ocasiona a violação de direitos humanos fundamentais, tais como respeito, igualdade, liberdade de expressão, entre outros (Borrilo, 2009; Rios, 2009; Rodrigues, 2011).

Visto que: “. . . À semelhança de qualquer outra forma de intolerância, a homofobia articula-se em torno de emoções (crenças, preconceitos, convicções, fantasmas...), de condutas (atos, práticas, procedimentos, leis...) e de um dispositivo ideológico (teorias, mitos, doutrinas, argumentos de autoridade...)" (Borrilo, 2010, pp. 34-35).

Assim, pode-se notar que a homofobia “. . . está tão arraigada na educação que, para superá-la, impõe-se um verdadeiro exercício de desconstrução de nossas categorias cognitivas . . ." (Borrilo, 2010, p. 87). Para tanto, pode-se partir da promoção de conhecimentos que levem ao questionamento dessa violência e a reconstrução dos saberes e práticas que compõem as representações dos/as docentes.

\section{Considerações Finais}

Pôde-se notar que a homofobia é um fenômeno complexo e, portanto, não possui somente uma causa, visto que suas variadas práticas (diretas ou indiretas) são ocasionadas, reforçadas e mantidas por diversos fatores históricos e socio- 
culturais fundamentados, sobretudo, em crenças, mitos, tabus e preconceitos em torno da sexualidade e do gênero que insistem em conservar o modelo heterossexual como hegemônico.

Desse modo, as representações dos/as docentes acerca da homofobia estão alicerçadas em diversas normatizações que compõem a realidade social, e quando aceitas sem questionar ou problematizar podem fomentar preconceitos e discriminações contra a diversidade sexual.

A formação docente inicial e continuada pode possibilitar estudos sistemáticos, críticos e conhecimentos abrangentes acerca das temáticas sexualidade, diversidade sexual, gênero e homofobia. $\mathrm{E}$ assim, contribuir de modo significativo com a desconstrução de representações ancoradas em preconceitos e estereótipos, permitindo transformações cognitivas e sociais que promovam o (re)conhecimento da pluralidade de indivíduos que perpassa o âmbito escolar, bem como a criação de estratégias para o enfrentamento de todas as formas de homofobia.

Ademais, esse estudo evidencia a necessidade de mais pesquisas nesse campo, que educadores/as e pesquisadores/as de diversas áreas se interessem por essas temáticas, busquem (in) formações significativas que auxiliem no combate à homofobia (re)produzida no espaço escolar. Enfatiza-se a extrema relevância de haver uma avaliação da formação docente com relação à sexualidade e gênero considerando a complexidade de elementos que os constituem. Ademais, destaca-se a necessidade de investimento em ações significativas, como a reformulação do currículo das licenciaturas, com a inclusão dessas temáticas (a exemplo do que já ocorreu na Universidade Federal de Sergipe no curso de Biologia) e intervenções nas escolas que possibilitem a inserção das temáticas relativas à diversidade sexual e a desconstrução das práticas homofóbicas.

\section{Referências}

Abramovay, M., Castro, G. M., \& Silva, L. B. (2004). Juventudes e sexualidade. Brasília, DF: Organização das Nações Unidas para a Educação, a Ciência e a Cultura Brasil.
Bardin, L. (2011). Análise de conteúdo. Lisboa, Portugal: Edições 70.

Borrilo, D. (2009). A homofobia. In T. Lionço \& D. Diniz (Eds.), Homofobia \& Educação: Um desafio ao silêncio (pp. 15-46). Brasília, DF: LetrasLivres.

Borrilo, D. (2010). Homofobia: História e crítica de um preconceito. Belo Horizonte, MG: Autêntica.

Cavaleiro, C. M. (2009). Escola e sexualidades: Alguns apontamentos para reflexões. In M. N. D. Figueiró (Ed.), Educação sexual: Em busca de mudanças (pp. 153-169). Londrina, PR: Universidade Estadual de Londrina.

Chaves, A. M., \& Silva, P. L. (2011). Representações sociais. In A. R. R. Torres, L. Camino, M. E. O. Lima, \& M. E Pereira (Eds.), Psicologia social: Temas e teorias (pp. 299-349). Brasília, DF: Technopolitik.

Chochík, J. L. (2006). Preconceito, indivíduo e cultura (3. ed.). São Paulo, SP: Casa do Psicólogo.

Conselho Nacional de Combate à Discriminação, \& Ministério da Saúde. (2004). Brasil sem homofobia: Programa de combate à violência e à discriminação contra GLTB e promoção da cidadania homossexual. Brasília, DF: Ministério da Saúde.

Dinis, F. N. (2012). Educação e diversidade sexual: Interfaces Brasil/Canadá. Revista Educação e Cultura Contemporânea, 9(18), 75-96.

Fleury, A. R. D., \& Torres, A. R. R. (2010). Homossexualidade e preconceito: O que pensam os futuros gestores de pessoas. Curitiba, PR: Juruá.

Furlani, J. (2009). Direitos Humanos, Direitos Sexuais e Pedagogia Queer: O que essas abordagens têm a dizer à Educação Sexual? In R. D. Junqueira (Ed.), Diversidade sexual na Educação: Problematizações sobre a homofobia nas escolas (pp. 293-324). Brasília, DF: Organização das Nações Unidas para a Educação, a Ciência e a Cultura.

Herek, G. M. (2000). The psychology of sexual prejudice. Current Directions in Psychological Science, 9, 19-22. doi:10.1111/1467-8721.00051

Jodelet, D. (1993). Representações sociais: Um domínio em expansão (T. B. Mazzotti, Trad., \& A. J. Alves-Mazzotti, Revisão Técnica). In D. Jodelet (Ed.), As representações sociais. Rio de Janeiro, RJ: Universidade Federal do Rio de Janeiro, Faculdade de Educação. (Mimeo reproduzida de Les représentations sociales, pp. 31-61, de D. 
Jodelet, Ed., 1989, Paris, Presses Universitaires de France)

Jovchelovitch, S. (2008). Vivendo a vida com os outros: Intersubjetividade, espaço público e representações sociais. In P. A. Guareschi \& S. Jovchelovitch (Eds.), Textos em representações sociais (10. ed.,pp. 63-85). Petrópolis, RJ: Vozes.

Junqueira, R. D. (2009). Educação e homofobia: O reconhecimento da diversidade sexual para além do multiculturalismo liberal. In R. D. Junqueira (Ed.), Diversidade sexual na Educação: Problematizações sobre a homofobia nas escolas (pp. 367-444). Brasília, DF: Ministério da Educação, Secretaria de Educação Continuada, Alfabetização e Diversidade.

Koehler, S. M. F. (2009, set./dez.). Representação social da homofobia na cidade de Lorena/SP. Revista Diálogo Educacional, 9(28), 587-604.

Lima, M. E. O. (2011). Preconceito. In A. R. R. Torres, L. Camino, M. E. O. Lima, \& M. E Pereira (Eds.), Psicologia Social: Temas e teorias (pp. 451-500). Brasília, DF: Technopolitik.

Lima, M. E. O., \& Vala, J. (2004). As novas formas de expressão do preconceito e do racismo. Estudos de Psicologia (Natal), 9(3), 401-411.

Louro, G. L. (1997). Gênero, sexualidade e educação: Uma perspectiva pós-estruturalista (2. ed.). Petrópolis, RJ: Vozes.

Louro, G. L. (2000). Pedagogias da sexualidade. In G. L. Louro (Ed.), O corpo educado: Pedagogias da sexualidade (2. ed., pp. 7-34). Belo Horizonte, MG: Autêntica.

Louro, G. L. (2001). Teoria queer: Uma política pós-identitária para a educação. Revista Estudos Feministas (Florianópolis), 9(2), 541-553. doi:10.1590/S0104-026X2001000200012

Louro, G. L. (2009). Heteronormatividade e homofobia. In R. D. Junqueira (Ed.), Diversidade sexual na Educação: Problematizações sobre a homofobia nas escolas (pp. 85-94). Brasília, DF: Ministério da Educação, Secretaria de Educação Continuada, Alfabetização e Diversidade.

Madureira, A. F. A. (2007). Gênero, sexualidade e diversidade sexual na escola: A construção de uma cultura democrática (Tese de doutorado, Universidade de Brasília, DF, Brasil).

Minayo, M. C. S. (2008). O conceito de representações sociais dentro da Sociologia Clássica. In P. A. Guareschi \& S. Jovchelovitch (Eds.), Textos em representações sociais (10. ed., pp. 89-111). Petrópolis, RJ: Vozes.
Moscovici, S. (2010). Representações sociais: Investigações em Psicologia Social (7. ed.). Petrópolis, RJ: Vozes.

Nardi, H. C. (2010). Educação, heterossexismo e homofobia. In F. Pocahy (Ed.), Politicas de enfrentamento ao heterossexismo: Corpo e prazer (pp. 151-167). Porto Alegre, RS: Nuances.

Prado, M. A. M., \& Junqueira, R. D. (2011). Homofobia, hierarquização e humilhação social. In G. Venturi \& V. Bokany, Diversidade sexual e homofobia no Brasil (pp. 51-71). São Paulo, SP: Editora da Fundação Perseu Abramo.

Rios, R. R. (2009). Homofobia na perspectiva dos direitos humanos e no contexto dos estudos sobre preconceito e discriminação In R. D. Junqueira (Ed.), Diversidade sexual na Educação: Problematizações sobre a homofobia nas escolas (pp. 53-84). Brasília, DF: Ministério da Educação, Secretaria de Educação Continuada, Alfabetização e Diversidade.

Rodrigues, J. (2011). Direitos humanos e diversidade sexual: Uma agenda em construção. In G. Venturi \& V. Bokany, Diversidade sexual e homofobia no Brasil (pp. 23-38). São Paulo, SP: Editora da Fundação Perseu Abramo.

Scardua, A., \& Souza, E. A., Filho. (2006). O debate sobre a homossexualidade mediado por representações sociais: Perspectivas homossexuais e heterossexuais. Psicologia: Reflexão e Crítica, 19(3), 482-490. doi:10.1590/S010279722006000300017

Secretaria de Direitos Humanos. (2012). Relatório sobre violência homofóbica no Brasil: $O$ ano de 2011. Brasília, DF: Autor.

Secretaria de Educação Fundamental. (1999). Parâmetros curriculares nacionais: Orientação sexual. Brasília, DF: Autor.

Silva, J., Jr. (2010). Rompendo a mordaça: Representações sociais de professores e professoras do ensino médio sobre homossexualidade (Tese de doutorado, Faculdade de Educação, Universidade de São Paulo, SP, Brasil).

Tosso, M. P (2012). Formación del profesorado en la atención a la diversidad afectivo-sexual (Tesis doctoral, Faculdad de Educación, Universidad Complutense de Madrid, España).

Recebido: 14/03/2014

$1^{a}$ revisão: 14/07/2014

Aceite final: 08/08/2014 